\title{
A experiência de alunos do PET-Saúde com a saúde indígena e o programa Mais Médicos
}

\author{
Reijane Pinheiro da Silva(a) \\ Aline Costa Barcelos ${ }^{(b)}$ \\ Bruno Queiroz Luz Hirano(c) \\ Renata Sottomaior Izzo(d) \\ Jaqueline Medeiros Silva Calafate(e) \\ Tássio de Oliveira Soares ${ }^{(\mathfrak{)})}$
}

\section{Introdução}

\section{O Programa PET-Saúde}

Lançado em 2009, o Programa de Educação pelo Trabalho para a Saúde (PET-Saúde), inicialmente como PET-Saúde da Família, tem como fio condutor a integração ensino-serviço-comunidade e a indissociabilidade ensino, pesquisa e extensão. É uma parceria entre: a Secretaria de Gestão do Trabalho e da Educação na Saúde (SGTES), Secretaria de Atenção à Saúde (SAS) e Secretaria de Vigilância em Saúde (SVS) do Ministério da Saúde; a Secretaria de Educação Superior (SESU) do Ministério da Educação; e a Secretaria Nacional de Políticas sobre Drogas (Senad/GSI/PR). O PET-Saúde da Família teve como princípios a integralidade e a humanização do cuidado na Atenção Primária à Saúde, no trabalho articulado com a Estratégia de Saúde da Família. De 2009 até 2012, foram apoiados 334 projetos nas áreas da Estratégia Saúde da Família, Vigilância em Saúde e Saúde Mental'1.

O PET-Saúde é uma inovação pedagógica que agrega os cursos de graduação da área da Saúde e fortalece a prática acadêmica que integra a universidade, em atividades de ensino, pesquisa e extensão, com demandas sociais de forma compartilhada. Realiza-se como educação interprofissional, onde estudantes de diferentes formações e que estão em diversos períodos em suas graduações, mediados por professores de várias formações e profissionais dos serviços, aprendem e interagem em conjunto visando à melhoria da qualidade no cuidado à saúde das pessoas, famílias e comunidades. Valoriza o trabalho em equipe, a integração e as especificidades de cada profissão'.

Profissionais de Saúde do SUS, docentes e estudantes de graduação da área da Saúde compõem o público-alvo do Programa. Os projetos são desenvolvidos por instituições de Educação Superior em parceria com secretarias de Saúde. O PETSaúde tem produzido intervenções nas quais estudantes, docentes, profissionais dos serviços de Saúde e comunidade são protagonistas. Além de atividades periódicas nos cenários de práticas da rede pública de serviços de Saúde, todos os integrantes dos projetos PET-Saúde desenvolvem pesquisas em temas prioritários para o SUS. O programa oferece bolsa de monitoria para acadêmicos, de tutoria para professores das universidades, e de preceptoria para os profissionais ligados ao serviço'. 
No final de 2011, a SGTES lançou um edital conjunto Pró-Saúde e PET-Saúde. O edital incentivou a apresentação de propostas que contemplassem as políticas e as prioridades do Ministério da Saúde, tais como: Rede Cegonha, Rede de Urgência e Emergência, Rede de Atenção Psicossocial, Ações de Prevenção e Qualificação do Diagnóstico e Tratamento do Câncer de Colo de Útero e Mama, Plano de Enfrentamento das Doenças Crônicas não Transmissíveis. Estes programas têm possibilitado vivências que ampliam a visão de professores, estudantes e profissionais do serviço sobre o cuidado ao sujeito que adoece no contexto de sua existência, colaborando para a escuta permeada por dúvidas, encantamentos e descobertas do imprevisível, qualificando a Atenção à Saúde que valoriza a relação entre humanos ${ }^{1}$.

A partir de 2013, foram incorporados 197 Grupos PET-Saúde/Vigilância em Saúde (PET/VS). Na sequência, foram iniciadas as atividades do PET-Saúde/Redes de Atenção (PET/Redes), cujos projetos foram selecionados em edital lançado em 2013. Foram aprovados 114 projetos com apoio a duzentos e noventa grupos PET. Considerando os três editais vigentes, existem, atualmente, 902 grupos PETSaúde com participação de 902 tutores, 4.624 preceptores e 10.036 estudantes 1 .

Dentro desse contexto o PET-Saúde Indígena faz parte do PET- Saúde/ Redes de Atenção, que se iniciou em 2013. O grupo é composto por acadêmicos da Universidade Federal de Tocantins (UFT) dos cursos de enfermagem, medicina, serviço social e nutrição. com a tutoria de uma antropóloga e professora da UFT do curso de Nutrição. A proposta do trabalho surgiu em resposta às demandas das aldeias, entre elas Porteira, Salto e Funil, e em consonância com os interesses de atuação dos discentes. Por meio da intermediação dos alunos Akwẽ-Xerente, foi apresentado e discutido com as lideranças e com os agentes de saúde das aldeias citadas. Nestas discussões foi apresentado e submetido ao parecer do grupo, que o acolheu e demonstrou muito interesse na sua implementação.

Os alunos, por sua vez, participaram ativamente da elaboração da proposta e das reuniões de estudo sobre o contexto cultural e econômico e, especialmente, sobre as condições de saúde do Povo Indígena Xerente. A partir destas discussões e cientes das particularidades do trabalho em uma área cultural indígena, o grupo vem fazendo ações de saúde nas aldeias Xerente, bem como estudando e conhecendo mais sobre a cultura e saúde nesse contexto. Além de estudarem sobre as questões que levam ao uso de álcool nas aldeias, objetivo principal do projeto, os acadêmicos realizam oficinas de educação em saúde, procurando conhecer a comunidade e o serviço de saúde oferecido, visto que a saúde é complexa e interligada a várias questões socioculturais e ambientais.

Assim, o projeto PET-Saúde Indígena pretende contribuir com um trabalho educativo com a promoção da saúde coletiva: valorizando os preceitos da cultura, informando sobre os efeitos negativos do álcool na saúde dos indivíduos e da coletividade, e, também, realizando trabalhos em educação em saúde, aproximação com a comunidade e com o serviço de saúde, contribuindo para a promoção da saúde de forma geral, uma vez que o alcoolismo é um sintoma de problemas mais amplos, como a desvalorização e marginalização da cultura em relação à sociedade envolvente, além de estar ligado a um serviço de saúde forte, comprometido e bem interligado com essas questões.

A orientação dos profissionais da rede de saúde e monitoria dos alunos envolvidos dos cursos de serviço social, medicina, enfermagem e nutrição possibilitou o estabelecimento de um debate permanente sobre saúde entre os indígenas, permitindo, também, o intercâmbio e a formação para a diversidade dos estudantes.

No mês de maio de 2014, o grupo realizou atividades de articulação com o DSEI (Distrito Sanitário Especial Indígena) para a participação na Ação de Intensificação das atividades de saúde, a qual incluiu: ações educativas sobre higiene pessoal, saúde bucal e alimentação, consultas de rotina para populações indígenas, aferição de pressão em adultos, e desenvolvimento nutricional de crianças. Neste contexto, os alunos de medicina da Universidade Federal do Tocantins integrantes do PETSaúde Indígena tiveram a oportunidade de acompanhar os profissionais de saúde que compõem a equipe de Saúde da Família (médicos, enfermeiros e técnicos de enfermagem) durante o atendimento à população Akwẽ-Xerente da aldeia Funil. O objetivo geral desta participação foi o de aproximar os acadêmicos, comunidade indígena e o serviço de saúde, buscando compreender o funcionamento das diversas estruturas relacionadas. Dentre os objetivos específicos, pretende-se perceber as dificuldades dos diversos profissionais, bem como reconhecer as diversas experiências exitosas nesse contexto, procurando criar um senso crítico em relação ao sistema de saúde. Objetiva-se, ainda, criar soluções e 
participar ativamente do processo, permitindo uma melhor formação acadêmica, uma compreensão e melhoria do sistema de saúde e uma aproximação e melhor conhecimento da comunidade inserida.

\section{Caracterização do povo Akwẽ-Xerente}

Os Akwẽ, ou Xerente, formam uma população indígena com aproximadamente 3.600 pessoas, que vivem em 64 aldeias (ou grupos familiares) situadas no município tocantinense de Tocantínia. Todos falam a língua Akwẽ ou Xerente, a qual pertence ao tronco Macro-jê e à família Jê. Historicamente, o povo Akwẽ-Xerente, como os demais povos indígenas da região, teve sua população drasticamente reduzida ${ }^{2}$.

Trata-se de um grupo que, desde 1824, vem sofrendo uma redução drástica da população: em 1824, eram quatro mil; em 1900, mil trezentos e sessenta; em 1929, oitocentos; e, em 1957, trezentos e cinquenta. De acordo com Braggio (1999), atualmente, os Akwẽ-Xerente estão sendo cada vez mais pressionados, pois suas terras encontram-se exatamente no caminho da expansão do Estado do Tocantins, a partir da criação de sua capital, Palmas, em $1988^{2}$.

O cerrado dá subsistência ao povo Akwẽ-Xerente. Eles caçam, coletam e associam essas práticas com uma agricultura de coivara que complementa sua alimentação. A coleta constitui de itens como mel, frutos, raízes variadas e plantas medicinais. A pesca é uma prática comum dos Akwẽ-Xerente, mas tem sofrido declínio pelos impactos das barragens no rio Tocantins. A caça também diminuiu bastante em virtude das pressões sobre os recursos naturais. As queimadas são também uma realidade. Tal contexto os direcionam para outras buscas de sobrevivência, em sua maioria, similar às buscas dos povos não indígenas ${ }^{3}$.

Atualmente, a confecção e o comércio de artesanatos oriundos do capim-dourado têm sido uma das principais atividades desenvolvidas. Cestaria, bordunas, arcos e flechas, colares também são comercializados na região. Além do comércio, o povo Akwẽ-Xerente tem atuado em cargos de motoristas e ajudantes de postos conquistados junto à FUNAI, e também como agentes indígenas de saúde e de saneamento, como professores, dentre outros. Outros recursos são obtidos por meio da previdência, o que possibilita o consumo nos mercados de Tocantínia, já que muitos já não podem manter o ritmo de trabalho na roça ${ }^{3}$. E ainda há uma parcela considerável dessa população que acessa recursos de política de transferência e distribuição de renda por meio do Programa Bolsa Família.

Historicamente, os Akwẽ-Xerente enfrentaram vários processos de violência praticados pela sociedade envolvente, inclusive, tentativa de extermínio, além das interferências culturais indiretas que desorganizaram e desorganizam as referências culturais tradicionais desse povo. Entre estas, a introdução do álcool foi e é amplamente utilizada como forma de dominação e marginalização dos indígenas, especialmente quando interesses relativos ao uso da terra estão em jogo. A introdução do álcool e de outras drogas nas aldeias indígenas se deu simultaneamente à convivência com a sociedade envolvente, que, no caso dos Akwẽ-Xerente, ultrapassa duzentos anos.

Apesar do contexto desfavorável, os Akwẽ-Xerente se mobilizaram para garantir o direito às suas terras e se mostram muito articulados politicamente por meio de diversas associações indígenas e com representação nos espaços voltados para elaboração e implementação de políticas públicas voltadas para os seus interesses, como a Secretaria Especial de Saúde Indígena (SESAI) e os Distritos Especiais Sanitários Indígenas (DSEI). Quantos aos aspectos relativos à saúde, os dados de 2013 do Distrito Sanitário Especial Indígena Tocantins (DSEI - TO) mostram que hipertensão e diabetes são doenças crônicas emergentes entre os Akwẽ-Xerente, o que demanda uma atenção especial. Um levantamento recente do DSEI Tocantins também aponta o álcool com um problema significativo, preocupação que também afeta as lideranças indígenas, professores e agentes de saúde.

Além dos problemas de saúde agravados com o uso do álcool, as representações de que os indígenas são alcoólatras e preguiçosos são reforçadas pela presença de indivíduos alcoolizados na praça principal da cidade. De acordo com um representante da comunidade, ver os indígenas deixados na praça é como um golpe na cultura. Ele relata que é muito triste para a comunidade e faz com que os brancos discriminem ainda mais o indígena, como se todos fossem bêbados. 


\section{O Programa Mais Médicos para o Brasil}

O Programa Mais Médicos para o Brasil foi instituído pela Lei no 12.871, de 22 de outubro de 2013, com várias frentes para resolver os problemas existentes na assistência médica das Unidades Básicas de Saúde (UBS). Observa-se, no País, uma enorme disparidade da relação de médicos/mil habitantes entre os Estados. Assim, além de uma questão distributiva, enfrenta-se também uma escassez na oferta de médicos. Notadamente, a saúde básica requer uma proporção maior de médicos por equipamento em relação à medicina especializada, tornando relevante a discussão do uso de recursos para a contratação de novos trabalhadores ${ }^{4}$.

Essa ação foi motivada por um retrato estatístico do sistema de saúde que evidencia, entre outros aspectos, a má relação médicos por habitante no País. Segundo o Instituto de Pesquisa Econômica Aplicada (IPEA), a média nacional de médicos por mil habitantes é de 1,8, média abaixo dos países vizinhos, como Uruguai $(3,7)$, Argentina $(3,2)$ e de países desenvolvidos, como Alemanha $(3,6)$, Reino Unido $(2,7)$ e Estados Unidos $(2,4)^{5}$. Neste contexto, o Programa Mais Médicos é parte de uma série de medidas adotadas pelo governo federal com o intuito de melhorar a qualidade e capacidade de atendimento do Sistema Único de Saúde (SUS). O programa visa aumentar o número de médicos por mil habitantes, sobretudo em regiões do país onde a população ainda é pouco assistida e, também, nas periferias de grandes centros.

Com essas questões em mente, ações com efeito de longo prazo foram adotadas com a intenção de expandir as faculdades de medicina no país, além de ampliar o número de vagas nos cursos de graduação de residência. Neste sentido, trabalha-se em diferentes frentes: desde políticas educacionais nos cursos de medicina, estímulo à pesquisa aplicada ao SUS, e inserção de médicos em regiões prioritárias para o SUS. Essa inserção de médicos, inclusive com a vinda de estrangeiros, trata-se da parte emergencial e medida de curto prazo para amparar as regiões mais necessitadas do País e gerar impactos sobre seus indicadores de saúde ${ }^{4}$.

Dentre os objetivos específicos deste trabalho, há também a intenção de identificar diferenças culturais e na formação acadêmica de profissionais estrangeiros advindos do programa Mais Médicos, e de que forma elas poderiam impactar na relação com os pacientes indígenas.

\section{Metodologia}

A proposta metodológica do PET-Saúde Indígena da UFT é permeada pela perspectiva da observação participante, sustentada nos parâmetros antropológicos do trabalho de campo. A premissa fundamental é a de que os pesquisadores estejam inseridos na realidade que pretendem apreender, registrem e deem visibilidade às interpretações dos pesquisados, tornando-os interlocutores do campo de pesquisa ${ }^{6}$. Diante dessa orientação, a inserção dos pesquisadores e extensionistas no cotidiano do trabalho do DSEI - TO teve início por meio de três etapas de capacitação dos alunos e preceptores para a atuação conjunta. Considerando a necessidade de que o grupo se apropriasse do conhecimento produzido acerca das especificidades culturais do povo em questão, foram indicadas as referências bibliográficas produzidas no âmbito da antropologia, etnologia e antropologia da saúde. Em um segundo momento, alunos e preceptores participaram de uma capacitação na aldeia indígena Funil, em que as lideranças indígenas conduziram o trabalho, apresentando sua organização social, política e realidade econômica. A terceira etapa de capacitação foi realizada na aldeia Porteira, e também contou com a participação efetiva das lideranças indígenas e pajés Akwẽ-Xerente. Após essa aproximação inicial, os alunos foram orientados a atuar no seu campo de interesse, sem deixar de participar de outras atividades propostas pelos preceptores, estreitando, assim, a relação ensino-serviço-comunidade. O fato de o início do PET-Saúde Indígena ter coincidido com o início do Programa Mais Médicos para o Brasil permitiu que os alunos problematizassem a presença desses novos atores em uma realidade tão complexa quanto a saúde indígena. Considerando a questão levantada pelos alunos de Medicina, a tutoria do projeto sugeriu que eles acompanhassem os profissionais médicos intercambistas recém-chegados a fim de perceberem como se daria a dinâmica do trabalho em atenção básica em uma perspectiva multicultural. 
Considerando que a proposta da extensão é articular o conhecimento produzido na Universidade, com as necessidades e desafios impostos pela vida em sociedade, a inserção em campo possibilitou, aos alunos, que refletissem sobre a realidade que estavam vivenciando, problematizando-a criticamente, como propõe o Plano Nacional de Extensão Universitária:

A Extensão Universitária é o processo educativo, cultural e científico que articula o Ensino e a Pesquisa de forma indissociável e viabiliza a relação transformadora entre universidade e sociedade. A Extensão é uma via de mão dupla, com trânsito assegurado à comunidade académica, que encontrará, na sociedade, a oportunidade de elaboração da práxis de um conhecimento académico. No retorno à Universidade, docentes e discentes trarão um aprendizado que, submetido à reflexão teórica, será acrescido àquele conhecimento. Esse fluxo, que estabelece a troca de saberes sistematizados, académico e popular, terá como consequência: a produção do conhecimento resultante do confronto com a realidade brasileira e regional; a democratização do conhecimento académico e a participação efetiva da comunidade na atuação da Universidade. Além de instrumentalizadora desse processo dialético de teoria/prática, a Extensão é um trabalho interdisciplinar que favorece a visão integrada do social. ${ }^{7}$ (p. 9)

A experiência, em linhas gerais, se deu por intermédio da participação dos acadêmicos nas consultas médicas, com orientação dos médicos intercambistas do Programa Mais Médicos. Na ocasião, os bolsistas acompanharam visitas e consultas médicas, conversaram com os pacientes, tiveram contato com a realidade dos consultórios médicos dentro das aldeias e com os profissionais médicos e técnicos de enfermagem, tendo acesso à realidade dos medicamentos e exames disponíveis, e também conheceram a realidade vivida pela população indígena. Essa experiência propiciou o levantamento de questões que posteriormente foram discutidas nas reuniões do PET-Saúde e motivaram a sistematização de propostas para uma aproximação mais efetiva da realidade da atenção básica na área indígena.

\section{Resultados e discussão}

\section{As condições de trabalho}

Com relação às condições de trabalho dos médicos e demais profissionais da equipe multidisciplinar de saúde, responsáveis pela aldeia Funil, podem-se perceber várias carências tanto da estrutura física, insumos e disponibilidade de profissionais. A estrutura física da Unidade Básica de Saúde destinada ao atendimento da população da aldeia Funil está muito aquém do preconizado pelo Ministério da Saúde para a alocação de uma equipe de Saúde da Família. A unidade lá presente é composta por uma sala de espera, um sanitário para usuários e um consultório apenas, representando um número bem abaixo conforme o sugerido pelo Manual de Estrutura Física das Unidades Básicas de Saúde ${ }^{8}$ apresentado na Tabela 1.

A análise individual de cada setor revela, mais uma vez, condições indesejáveis tanto de trabalho quanto de acolhimento para os pacientes. A sala de espera possui poucas cadeiras e apenas um banco de alvenaria para a alocação dos pacientes, não sendo capaz de atingir o preconizado de alocar vinte pessoas aproximadamente. O consultório não tem armários e os medicamentos e insumos ficam armazenados em caixas ou recipientes improvisados. A falta de medicamentos foi outro problema encontrado e muito ressaltado pelo médico. Havia poucas opções de classes farmacêuticas, e fórmulas não utilizadas pela população indígena local encontravam-se disponíveis - foi o caso de um colírio umidificador para lentes de contato. Com relação aos profissionais, segundo dados do Distrito de Sanitário de Saúde Especial Indígena Tocantins (DSEI-TO), a Equipe de Saúde da Família que atende à população Akwẽ-Xerente da aldeia Funil é composta por uma equipe permanente na unidade formada por: um enfermeiro, um técnico em enfermagem, um agente indígena de saúde e um agente 
indígena de saneamento; e, ainda, por outra parte que descola para atender todas as aldeias da região conforme a agenda do Polo Base Indígena de Tocantínia, sendo essa formada por: um médico, um dentista, um auxiliar de dentista e um técnico auxiliar.

Tabela 1. Estrutura sugerida para Unidade Básica de Saúde com uma Equipe de Saúde da Família

\begin{tabular}{lc}
\hline \multicolumn{1}{c}{ Ambientes } & Número de salas ou espaços \\
\hline Recepção para pacientes e acompanhantes & 1 \\
Sala de Espera para pacientes e acompanhantes & 1 a 3 \\
Consultório com sanitário & 1 \\
Consultório & 1 \\
Sala de procedimentos & 2 \\
Almoxarifado & 1 \\
Consultório odontológico com área para escovário & 1 \\
Área para compressor e bomba a vácuo & 1 \\
Área para depósito de material de limpeza (DML) & 1 \\
Sanitário (para usuários) & 2 \\
Copa/Cozinha alternativa & 1 \\
Sala de utilidades & 1 \\
Área para reuniões e educação em saúde & 1 \\
Abrigo de resíduos sólidos (Se a UBS proceder à esterilização local) & 1 \\
Sala de recepção, lavagem e descontaminação & 1 \\
Sala de esterilização e estocagem de material esterilizado & 1 \\
\hline
\end{tabular}

A disponibilidade de profissionais foi o aspecto mais alarmante dentre todos analisados. Apesar da iniciativa do programa Mais Médicos para o Brasil, o número de médicos alocados na aldeia representa uma quantidade insuficiente frente às necessidades dos Akwẽ-Xerente. Segundo relato do médico, são apenas dois profissionais para cobrir uma área que abrange 64 aldeias, ou seja, cada médico é responsável por 32 aldeias, sendo cada uma assistida durante um dia do mês apenas. Essa realidade dificulta a consolidação de uma política de promoção da saúde eficaz, uma vez que o contato com o paciente é limitado e as ações do médico são feitas de forma descontínua, contrariando os princípios do Plano Nacional de Promoção da Saúde, instituídos pelo Sistema Único de Saúde (SUS), e cujo objetivo é a ênfase na atenção primária9 . No entanto é mister relatar que, antes da contratação dos médicos do programa, as condições de atendimento médico encontravam ainda mais dificuldades, haja vista que os médicos tinham ainda menos tempo em área.

Nos outros dias em que não há médicos na unidade, essa fica sob a responsabilidade do enfermeiro-chefe, o qual, em situações em que não pode resolver a situação, encaminha o paciente para as cidades de Tocantínia, a sete quilômetros da aldeia (via terrestre) ou Miracema, a oito quilômetros (vias terrestre e fluvial), ou, em casos de necessidade de atendimento de alta complexidade, para a capital Palmas, a 73 quilômetros da aldeia (via terrestre).

\section{O impacto da presença de um médico estrangeiro na comunidade Akwẽ-Xerente}

A presença de um médico vindo de outra cultura, neste caso, ainda de outro país, na comunidade Funil, traz uma nova realidade no atendimento para a comunidade local. "Nesse momento, as diferentes visões de mundo se encontram e se confrontam, na tentativa de decodificar os significados do que cada uma entende do processo saúde/doença e das diferentes medidas terapêuticas"9 ( $p$ 21). 
Um dos impasses iniciais foi quanto ao tempo de consulta. Em um momento de aproximação com a comunidade Akwẽ-Xerente, os indígenas relatam que, no início, tinham a impressão de que as consultas dos médicos intercambistas eram muito breves. Uma enfermeira do Polo Base Indígena de Tocantínia explica que isso é devido a uma questão cultural Akwẽ-Xerente, a qual entende a doença como um processo acumulativo de eventos desde a infância - por isso os pacientes indígenas têm a necessidade de narrar eventos de toda sua vida que consideram determinantes para explicar o estado atual de saúde.

A dificuldade de comunicação foi outra questão levantada, uma vez que paciente e médico são falantes de idiomas completamente distintos. Os usuários indígenas relatam alguns momentos em que tiveram dificuldade em entender as falas dos médicos intercambistas, sobretudo na chegada deles à área, mas afirmam que essa dificuldade foi sendo superada com o passar do tempo. Os indígenas, sobretudo os mais velhos e muitas mulheres, essas por razões culturais, têm pouco domínio da língua portuguesa. Os médicos, por outro lado, não sabem a língua nativa, o Akwẽ-Xerente, e não têm total domínio do português, o que, muitas vezes, dificulta a comunicação entre médico e paciente. Nesse contexto, foi de importante destaque a participação de técnicos em enfermagem nativos que trabalham na unidade de saúde da comunidade, para auxiliar em momentos em que a comunicação estava prejudicada. Os usuários indígenas reconhecem que, sem a ajuda desses profissionais, os atendimentos eram comprometidos, sobretudo, ao terem de expressar o que estavam sentindo, como ocorreu no início do Programa Mais Médicos, o qual coincidiu com uma época em que ainda não havia técnicos nativos trabalhando nos postos de saúde. Os enfermeiros do polo relatam que, até então, cabia a eles intermediarem a comunicação entre médico e paciente, e que, muitas vezes, pediam auxílio, durante as consultas, para os acompanhantes que dominavam o idioma português.

Seria importante, uma vez que os médicos são destinados para áreas específicas, que eles recebessem um curso de capacitação sobre a cultura e a língua materna dos povos nativos, quando enviados para áreas indígenas, visto que esses grupos apresentam particularidades tanto culturais quanto linguísticas.

Por outro lado, a formação acadêmica dos médicos intercambistas apresenta diferenciais oportunos para o exercício da medicina no contexto das comunidades indígenas. Dentre eles, destaca-se o conhecimento sobre plantas medicinais. Segundo o médico, em seu país, é comum cursos de atualização sobre o uso de plantas em tratamentos terapêuticos e, na própria graduação, eles já têm um grande contato com essa área do conhecimento. Essa prática foi de extrema consonância com a realidade indígena, uma vez que o povo Akwẽ-Xerente tem, na base de sua cultura, a prática de utilização de plantas medicinais ${ }^{10}$, e que, na aldeia, há um acesso fácil a algumas espécies de plantas. O que no passado representava uma prática comum, hoje, tem sido substituído por uma forte medicalização. A capacitação de profissionais de saúde com o conhecimento sobre plantas medicinais poderia diminuir os custos para o sistema público e, consequentemente, minimizar os problemas de acesso a medicamentos devido a sua falta nas redes de saúde, resultando em uma fonte alternativa de tratamento para os usuários que são, na sua maioria, parte de uma população de baixa renda.

Outro aspecto importante é o costume de fazer visitas às casas da comunidade e avaliar não apenas o estado dos indivíduos, mas, também, suas condições de moradia, o que lhes proporcionam uma visão mais fidedigna e holística da saúde de seus pacientes. Os profissionais do polo afirmam que os médicos atentam-se para questões como: a presença de animais domésticos, presença de filtro e estrutura das casas. Uma enfermeira relata que os médicos conseguiram entender melhor o alto número de casos de patologias respiratórias na comunidade Akwẽ-Xerente após constatarem, a partir das visitas domiciliares, que era comum as moradias não terem janelas e, portanto, dificultarem a circulação de ar e predisporem ao acúmulo de fumaça no interior dos cômodos. Segundo a cultura Akwẽ-Xerente, a fumaça produzida pelo uso do fogão à lenha, presente em quase todas as casas, é um aliado no combate a mosquitos e animais, como cobras, pois os afugentam.

Os indígenas avaliam como positiva a vinda dos médicos para as aldeias, uma vez que, antes do estabelecimento do Programa Mais Médicos, os usuários eram obrigados a se deslocarem para as cidades de Miracema, Tocantínia ou Palmas. Muitos relatam, ainda, as dificuldades em terem de aguardar em filas de espera e, muitas vezes, terem de voltar, posteriormente, para consulta ou 
agendamento de exames. Um dos profissionais de saúde do polo acrescenta que aumentou a presença nas consultas e a adesão ao tratamento de doenças por parte dos usuários, pois muitos indígenas tinham resistência de se deslocarem à cidade para acompanhamento médico.

\section{Considerações finais}

A vivência com a área indígena Funil permitiu o contato com o trabalho do DSEl Tocantins e as dificuldades as quais eles enfrentam, no intuito de consolidar um serviço de qualidade para os AkwẽXerente. Apesar das tentativas do governo de amenizar alguns problemas da saúde pública, percebese que apenas a vinda de médicos intercambistas está muito aquém de solucioná-los. A falta de infraestrutura, contratação de mais profissionais, compromisso com a reposição de insumos são apenas alguns dos transtornos que têm de ser superados para a melhoria do serviço.

A experiência trouxe também reflexões muito ricas para a formação dos estudantes que estiveram em área. O PET-Saúde possibilitou o contato com a realidade de um entre os vários povos indígenas presentes em território nacional, além do aprendizado das particularidades culturais do povo Akwẽ-Xerente, que amplia a percepção de que cada grupo étnico, classe social e, mesmo, indivíduo apresenta peculiaridades e, "a partir dessa compreensão, faz-se necessária uma comunicação intercultural mais sensível, cuidadosa e, consequentemente, inteligível e dialógica"9 ( $p 32$ ). Dentre esses aspectos especificamente, a confrontação entre a formação acadêmica nacional com a dos médicos intercambistas presentes na aldeia possibilitou perceber a necessidade de uma formação com domínio maior sobre o efeito terapêutico de plantas medicinais e que priorize a atenção básica em detrimento de especialidade. Essa mudança de paradigma, além de auxiliar no tratamento dos grupos indígenas, constitui uma boa forma de amenizar os problemas de falta de medicamentos na rede pública e uma estratégia sensível ao cuidado com as práticas tradicionais deste povo, colaborando, assim, para o fortalecimento de sua cultura e a troca de saberes.

Dessa forma, essa ação, dentro do contexto do projeto PET-Saúde, pode proporcionar melhor vivência do serviço de saúde e da comunidade, permitindo uma melhor aproximação da Universidade dentro do processo. Os acadêmicos que participam dessa ação estão mais próximos do sistema, conhecem melhor a realidade da comunidade, têm mais capacidade de análise crítica da realidade, sabendo reconhecer as experiências exitosas e podendo opinar sobre aquilo que pode ser melhorado, percebendo que a atenção básica deve ser priorizada e melhor estruturada, em detrimento da valorização da busca da especialidade. A experiência complementa o conhecimento adquirido na academia e permite qualificar melhor o acadêmico para trabalhar no contexto da atenção básica futuramente, particularmente dentro da atenção indígena. 


\section{Colaboradores}

Os autores trabalharam juntos em todas as etapas da produção do manuscrito.

\section{Referências}

1. Ministério da Saúde (BR), Secretaria de Gestão do Trabalho e da Educação na Saúde. PET Saúde e Pró-Saúde. Brasília, DF: Ministério da Saúde; 2013 [acesso em 15 ago 2014]. Disponível em: www.saude.gov.br/sgtes/petsaude

2. Sousa Filho SM. Educação Akwẽ-Xerente (Jê): seus saberes e práticas frente aos modelos brasileiros de escolarização. In: Anais eletrônicos do $11^{\circ}$ Congresso Luso Afro Brasileiro de Ciências Sociais; 7-10 ago 2011 [acesso em 27 ago 2014]; Salvador, BA. Disponível em: http://www.xiconlab.eventos.dype.com.br/resources/ anais/3/1306863229_ARQUIVO_ArtigoXICONLAB-Sinval31-05.pdf

3.Shmidt R. Preceitos alimentares Xerente: saúde e doença segundo um ancião, uma anciã e um xamã. In: Anais do $1^{\circ}$ Seminário de Pesquisa da Faculdade de Ciências Sociais; 2010; Goiânia, GO. p. 692-701.

4. Garcia B, Rosa L, Tavares R. Projeto Mais Médicos para o Brasil: apresentação do programa e evidências acerca de seu sucesso. Bol Inf FIPE. 2014 [acesso em 27 ago 2014];1(402):26-35. Disponível em: http://www.fipe.org.br/publicacoes/downloads/ bif/2014/3_26-36-bea-etal.pdf

5. Ministério da Saúde (BR). Mais médicos. Brasília, DF: Portal da Saúde; 2013 [acesso 12 maio 2014]. Disponível em: http://portalsaude.saude.gov.br/index.php/cidadao/acoes-eprogramas/mais-medicos/mais-sobre-mais-medicos/5952-diagnostico-da-saude-no-brasil

6. Damatta R. Relativizando: uma introdução à antropologia social. Rio de Janeiro: Rocco; 1987.

7. Fórum de Pró-Reitores de Extensão das Universidades Públicas Brasileiras. Política nacional de extensão universitária. Manaus: Fórum de Pró-Reitores de Extensão das Universidades Públicas Brasileiras; 2012 [acesso 20 ago 2014]. Disponível em: https:// www2.ufmg.br/proex/content/download/452/2780/.../PNEU.pdf

8. Ministério da Saúde (BR), Secretaria de Atenção à Saúde, Departamento de Atenção Básica. Manual de estrutura física das unidades básicas de saúde: saúde da família. Brasília, DF: Ministério da Saúde; 2006. (Série A. Normas e manuais técnicos).

9. Silva BC. Profissionais de saúde em contexto indígena: os desafios para uma atuação intercultural e dialógica [Internet]. Antropos. 2013 [acesso 27 ago 2014] 5(6):336. Disponível em: http://revista.antropos.com.br/downloads/dez2013/Artigo-1Profissionais-de-saude-em-contexto-indigena-Cleonice-Barbosa-da-Silva.pdf

10. Paula LR. Xerente: modos de subsistência. In: Instituto Socioambiental. Povos indígenas no Brasil; 1999 [acesso 12 maio 2014]. Disponível em: http://pib. socioambiental.org/pt/povo/xerente/1172 
O Programa PET-Saúde foi lançado em 2009 e é uma iniciativa para melhorar o ensino, mediante práticas de promoção em saúde. O PET-Saúde Indígena faz parte desse contexto e é composto por um grupo de acadêmicos dos cursos da saúde da Universidade Federal do Tocantins, Brasil, com supervisão de preceptores. O grupo realiza ações nas aldeias no Município de Tocantínia, na comunidade indígena Akwẽ-Xerente. Esse povo vem sofrendo redução em sua população, além do crescente aumento do uso de álcool e de doenças crônicas. Em 2013, O Ministério da Saúde lançou o programa Mais Médicos a fim de garantir o aumento de médicos em regiões prioritárias, e as aldeias em estudo foram incluídas. Dessa maneira, o artigo aborda a experiência dos acadêmicos de medicina no contato com esses profissionais por meio das atividades de ação em saúde nas aldeias.

Palavras-chave: Programas nacionais de saúde. Saúde de populações indígenas. Atenção primária à saúde. Eucação em saúde.

\section{The experience of PET-Health students with indigenous health and the More Doctors Program}

The PET-Health Program was launched in 2009 and is an initiative to improve education through health promotion practices. Indigenous PET-Health is a part of this program and comprises a group of academic health courses at the Federal University of Tocantins, Brazil, under the supervision of preceptors. The group performed actions in villages of the Tocantínia municipality in the Akwẽ-Xerente indigenous community. There was a population reduction, as well as an increase in alcohol use and in chronic diseases in this municipality. In 2013, the Ministry of Health launched the More Doctors Program to ensure an increase of physicians in priority regions; these villages were included in the study. Therefore, this paper addresses the experiences of medical students in touch with these professionals through action on village health activities.

Keywords: National health programs. Health of indigenous people. Primary health care. Health education.

\section{La experiencia de estudiantes del PET-Salud con la salud indígena y el programa Más Médicos}

El Programa PET-Salud lanzado en 2009 es una iniciativa para mejorar la educación a través de prácticas de promoción de la salud. El PET-Salud Indígena es parte de ese contexto y se compone de académicos en cursos de salud en la Universidad Federal de Tocantins, Brasil, con la supervisión de los preceptores. El grupo realiza acciones en los pueblos del municipio de Tocantínia, en comunidad Akwẽ-Xerente indígena, que está reduciendo su población, además de presentar un mayor consumo de alcohol y de enfermedades crónicas. En 2013, el Ministerio de Salud puso en marcha el programa Más Médicos para garantizar el aumento de médicos en regiones prioritarias, y las aldeas fueron incluidas en el estudio. El artículo aborda la experiencia de estudiantes de medicina en contacto con estos profesionales a través de la acción y actividades de salud en la aldea.

Palabras clave: Programas nacionales de salud. Salud de poblaciones indígenas. Atención primaria de salud. Educación en salud. 